\title{
Topography and biological noise determine acoustic detectability on coral reefs
}

E. F. Cagua

Red Sea Research Center, King Abdullah University of Science and Technology, Thuwal 23955, Saudi Arabia

$+255756534443$

edgar.cagua@kaust.edu.sa

M. L. Berumen

Red Sea Research Center, King Abdullah University of Science and Technology, Thuwal 23955, Saudi Arabia

Biology Department, Woods Hole Oceanographic Institution, Woods Hole, Massachusetts 02543, United States of America

+966544700019

Michael.berumen@kaust.edu.sa

E. H. M. Tyler

Red Sea Research Center, King Abdullah University of Science and Technology, Thuwal 23955, Saudi Arabia

Zoology Department, University of Cambridge, Downing Street, Cambridge CB2 3EJ, United Kingdom

+441638507447

ehtyler@gmail.com 
Acoustic telemetry is an increasingly common tool for studying the movement patterns, behaviour, and site fidelity of marine organisms, but to accurately interpret acoustic data, the variability, periodicity and range of detectability between acoustic tags and receivers must be understood. The relative and interactive effects of topography with biological and environmental noise have not been quantified on coral reefs. We conduct two long-term range tests (one and four months duration) on two different reef types in the central Red Sea, to determine the relative effect of distance, depth, topography, time of day, wind, lunar phase, sea surface temperature and thermocline on detection probability. Detectability, as expected, declines with increasing distance between tags and receivers, and we find average detection ranges of 530 and $120 \mathrm{~m}$, using V16 and V13 tags respectively, but the topography of the reef can significantly modify this relationship, reducing the range by $\sim 70 \%$, even when tags and receivers are in line-of-sight. Analyses that assume a relationship between distance and detections must therefore be used with care. Nighttime detection range was consistently reduced in both locations and detections varied by lunar phase in the four month test, suggesting a strong influence of biological noise (reducing detection probability up to $30 \%$ ), notably more influential than other environmental noises, including wind-driven noise, which is normally considered important in open-water environments. Analysis of detections should be corrected in consideration of the diel patterns we find, and range tests or sentinel tags should be used for more than one month to quantify potential changes due to lunar phase. Some studies assume that the most usual factor limiting detection range is weather-related noise; this cannot be extrapolated to coral reefs.

Passive monitoring, Acoustic transmitters, Detection efficiency, Saudi Arabia

\section{Introduction}

Passive monitoring of marine organisms with acoustic tags is now a widely used tool for investigating their movement patterns, site fidelity and habitat utilization (Humston et al. 2005; Heupel et al. 2006). Large numbers of individuals can be monitored in remote areas, for long periods of time, without the recapture effort commonly involved with other marking techniques. Since the development of smaller tags and increased battery life, allowing the study of smaller animals, this technique has become increasingly popular on coral reefs. 
Vemco (Amirix Corporation, Halifax, Canada) passive acoustic tags (which are widely used on coral reefs) emit encoded ultrasonic frequency sounds repeated at certain intervals (pings). Submerged fixed receivers listen for this signal at a distance. When the receiver successfully decodes a tag's signal, the time, the tag ID, and sensor measurements (if installed) are recorded. The factors that affect the likelihood of successfully detecting a tag (Detection Probability, DP) can be neatly summarized by the general sonar equation (in decibels [dB]): Signal to Noise Ratio = Source Level - Noise Level - Transmission Loss (Caruthers 1977). A higher signal to noise ratio (SNR) is reflected in a higher probability of detecting the tag. The source level is the sound intensity of the ping from the tag; the transmission losses represent the decrease in acoustic intensity of the signal as it propagates out of the tag, and the noise level is the sound intensity of background noise at the receiver.

Transmission losses are responsible for limiting the distance over which a receiver can detect a tag. This and other complex phenomena like shadowing, reflection and scattering, affect the detection probability (Heupel et al. 2006; Girard et al. 2008; Singh et al. 2009). Reflection and refraction are produced when there is a change in the sound transmission media, for example: shading caused by bottom topography, effects of submerged structures (rocks, kelp, corals), reflection with the water surface, with the shore and with different density layers in the water column, like the thermocline (Topping et al. 2006). While in some cases the thermocline can act as a sound channel that enhances detection efficiency (Siderius et al. 2007), some studies report lower detection efficiency when the thermocline is stronger (Singh et al. 2009).

Background underwater noise can be anthropogenic, biological or come from the sea surface (Wenz 1962). Surface noise, associated with rain and breaking waves, is better correlated to wind speed than to any other measure of sea state (Cato 2008). Ault et al. (2008) and How and de Lestang (2012) find a correlation between detection probability and water movement; 
other studies provide only anecdotal evidence of weather effects (e.g., Halttunen et al. 2009). Receivers usually contain filters that reduce their sensitivity outside a band that includes the tag's operational frequency (e.g., $69 \mathrm{kHz}$, the most commonly used frequency in Vemco passive telemetry equipment), therefore noises produced in this non-filtered band can have a major impact on Detection Probability (DP). Snapping shrimps (Alpheus and Synalpheus), mantis shrimps (Stomatopoda), and occasionally larger crabs (Cancer and Portunus), triggerfishes and grazing fish and urchins are able to produce sound in a broad frequency range that includes $69 \mathrm{kHz}$. Snapping shrimps, in particular, can be the dominant source of background noise in shallow tropical waters (Vijayabaskar and Rajendran 2010) and are found in coral reefs worldwide (Kennedy 2007). They are more active in darker periods like night and new moon, when they are less susceptible to predation (Radford et al. 2008) producing noise 2-5 dB higher (Morisaka et al. 2005).

Range tests are commonly performed before an acoustic tagging study to define the detection distance between receivers and tags, additionally they can help to a) optimize spatial arrangement of receivers, b) identify the detection efficiency decay function, c) determine the major factors affecting detectability at the study site and, d) identify the effect of factors that control the SNR. Heupel et al. (2006) extensively review the design of passive acoustic arrays. However range tests are often disregarded and detection ranges assumed (Welsh et al. 2012) and when range tests are performed, few last long enough to quantify temporal variability in DP. Sentinel tags (in a fixed location, usually programmed to ping at long intervals) can monitor performance during the study (Bradford et al. 2011), but they may collide with animal tags, and it is not possible to estimate detection range from them unless explicitly arranged for that purpose.

Despite the large number of studies using acoustic telemetry, and the number of factors in the study environment that can affect its performance, there has been little effort to quantify the 
effects of these factors. Efforts have mostly focused on the influence of design variables (e.g., receiver mounting method, location of the array, signal collision and measurements of performance; Clements et al. 2005; Simpfendorfer et al. 2008; Singh et al. 2009; Payne et al. 2010), and only recently have studies quantified the impact of environmental variables (e.g., Ault et al. 2008 and How and de Lestang 2012). Coral reefs present particular challenges for acoustic telemetry (Claisse et al. 2011), but even fewer studies had investigated the performance of acoustic arrays in these structurally complex environments (e.g., Welsh et al. 2012).

We therefore attempt to improve current understanding of the performance of coral reef acoustic telemetry by performing two comprehensive long-term range tests on different reef types in the Red Sea. These range tests also served to inform the design of two large scale tagging studies, one on whale sharks (using V16 tags) and the other on medium to large reef fish ( $\geq 26 \mathrm{~cm}$ total length, using V13 tags). These tags are relatively powerful compared to smaller tags (such as V9s) also used on coral reefs. We also measure a range of factors that could affect detections: distance between tags and receivers, receiver depth, tag depth, wind speed, thermocline, surface temperature, topographic features of the reef, as well as the diurnal and lunar cycle. We determine the relative influence of these factors on detection probability and the expected detection range between tags and receivers. To our knowledge this is the first study to analyze the comparative effect of all these factors on the performance of acoustic receivers in a coral reef environment.

\section{Methods}

\section{Study location}

Experiments were performed in two reefs located $50 \mathrm{~km}$ apart in the Farasan Banks in the central Red Sea coast of Saudi Arabia (Fig. 1 and Fig. 2). Malathu is a $0.3 \mathrm{~km}^{2}$ oceanic 
platform reef surrounded by water between 80 and $150 \mathrm{~m}$ deep, located $56 \mathrm{~km}$ offshore. It has near vertical reef walls with a sharply defined reef crest. The reef flat is relatively narrow with little topographic complexity and topped with a sandbank. We located the range test along a $330 \mathrm{~m}$ section of the northwest side of Malathu (Fig. 1c); this section is exposed to the predominant winds and is characterized by a wall with a near flat vertical profile, giving us line of sight along the whole section. Underwater visibility around the reef ranges from 25-40 m. The Shib Habil study site is a $400 \mathrm{~m}$ stretch of flat sandy bottom 20-30 m deep, with scattered coral patches, next to the north margin of Shib Habil, a $2.5 \mathrm{~km}^{2} 6-12 \mathrm{~m}$ deep barrier reef $4 \mathrm{~km}$ from shore (Fig. 2a). Underwater visibility ranges from 5-15 m, decreasing closer to the benthos.

\section{Experimental set-up and environmental variables}

\section{Malathu}

Short-term range tests in the study area (sea state condition Beaufort 3) revealed a maximum detection range of approximately $300 \mathrm{~m}$. We therefore installed ten receivers (VR2W $69 \mathrm{kHz}$, SNR $\approx 6-10 \mathrm{~dB}$, Vemco) $20-40 \mathrm{~m}$ apart, up to $335 \mathrm{~m}$ (at 0, 20, 61, 101, 140, 178, 212, 259, 292 and 335 m) from eight fixed delay tags (V13-1x-A69-1601, 69 kHz, signal level 153 $\mathrm{dB} @ 1 \mu \mathrm{Pa}$ at $1 \mathrm{~m}$, delay $480 \mathrm{~s}$, Vemco). Receivers were mounted at the end of $3 \mathrm{~m}$ long cantilever poles moored at $6 \mathrm{~m}$ depth just below the reef crest (Fig. 1d). Tags were attached to a vertically hanging weighted line hanging from the first receiver pole at 7, 14, 22, 29, 36, 43, 50 and $57 \mathrm{~m}$ depths (Fig. 1d). We used fixed delay tags activated at $1 \mathrm{~min}$ intervals, accounting for drift, to avoid collisions between transmissions. All equipment was installed on 8 June 2011 except for the third receiver from the Tagline, which was not installed until 6 July 2011 due to logistical issues; equipment was retrieved on 17 July 2011. 
To investigate the effect of reef topography on detectability, even when there was line-ofsight between our tag line and all the receivers, we defined a topographic index for each receiver as the minimum distance between a) the line between the tag line and each receiver and b) the curve that defines the reef contour. This curve was generated by a swimmer who followed the reef profile at $6 \mathrm{~m}$ depth while towing a surface GPS unit. The index ranged between 1.26 and $3 \mathrm{~m}$ (the mooring length was $3 \mathrm{~m}$ ). A hypothetical topographic index of 0 would correspond to a path that touches the reef.

As our receivers were mounted just below a sharply defined reef crest, we did not expect good detectability on the reef flat. However, because this area is heavily utilized by some fish species, we briefly tested the range of the array on the flat by installing tags at $0,10,16$ and $26 \mathrm{~m}$ from the crest adjacent to one of the receivers from 11:00 hrs 19 July to 12:00 hrs 20 July 2010.

We measured wind speed and direction in Malathu every $60 \mathrm{~s}$ with a wind logger (sensitivity $2.4 \mathrm{~km} \mathrm{~h}^{-1}$ turn ${ }^{-1}$, speed range 0 to $240 \mathrm{~km} \mathrm{~h}^{-1}$ ) and a wind vane (accuracy $22.5^{\circ}$ ) connected to a Waspmote Agricultural Sensor Board (Libelium S.L., Zaragoza, Spain).

Seven temperature data loggers (HOBO Pendant - UA-002-64) generated a temperature profile of the water column every $5 \mathrm{~min}$. The loggers were fixed to the tagline at $6,7,12,17$, 22, 27, 32 and $37 \mathrm{~m}$ depths.

\section{Shib Habil}

Nine VR2W receivers were deployed on five moorings (Fig. 2d). The first mooring held one receiver at $5 \mathrm{~m}$ depth, and two random delay coded tags $(\mathrm{V} 16 \mathrm{P}-6 \mathrm{H}, 60$ to $180 \mathrm{~s}$ delay, $160 \mathrm{~dB}$ (a) $1 \mu \mathrm{Pa}$ at $1 \mathrm{~m}$ ), at $5 \mathrm{~m}$ and $15 \mathrm{~m}$. The subsequent 4 moorings, each held one receiver with the hydrophone pointing down at $5 \mathrm{~m}$ and one pointing up at $15 \mathrm{~m}$. The shallow receiver of the fourth mooring was lost during the experiment and no data were retrieved. Equipment was installed on 28 March 2010 and retrieved on 21 July 2010. 
Daily averages of sea surface temperature were obtained from the NOAA Optimum Interpolation Daily Sea Surface Temperature Analysis at the NCDC (Reynolds et al. 2007). We used the fraction of the moon's visible disk illuminated by the sun for each day as an indicator of moon phase, where 1 corresponds to full moon and 0 corresponds to new moon. Values correspond to the illuminated fraction at midnight in the universal time zone as calculated by the Astronomical Applications Department of the U.S. Naval Observatory (http://aa.usno.navy.mil/data/docs/MoonFraction.php).

We did not include tidal data in either of our experiments because tidal amplitude during an epigean spring tide does not exceed $12.6 \mathrm{~cm}$ for Malathu and $11.2 \mathrm{~cm}$ for Shib Habil based on the HAMTIDE (Hamburg direct data Assimilation Methods for TIDEs) model.

\section{Data analysis}

The following analyses were applied to both reefs (specific details for each reef appear in the relevant sections below):to identify cyclical patterns in detections we performed a frequency analysis using a periodogram (Koopmans 1995) of the total added detections between all tags and receivers in $1 \mathrm{~h}$ bins. Peaks in the spectral density represent the dominant period at which the cyclic pattern occurs. To examine the relative influence of the measured variables on tag detectability, in each location, we modeled DP with a Generalised Linear Mixed Model (GLMM) with binomial error structure (cumulative logistic distribution) using a Penalized Quasi-Likehood method (R-package glmmPQL, Venables and Ripley 2002), which allowed us to specify a variance structure that included both random effects and temporal correlation. Although other relationships between detection probability (DP) and distance have been previously used (e.g., linear or near-gaussian; Hobday and Pincok 2011; Melnychuck 2012), there is evidence that this relationship is best described by a logistic regression (Szedlmayer and Schroepfer 2005; Melnychuk and Walters 2010; How and de Lestang 2012). R 3.0.1 (R Development Core Team 2011) was used for data processing and statistical analyses. 


\section{Malathu}

Using a GLMM, we modeled the detection probability calculated in $3 \mathrm{~h}$ bins. We chose bins that accommodated both the dominant peak at a $24 \mathrm{~h}$ period detected by the spectral analysis (Electronic supplementary material, ESM Fig. S1a) and the sunrise and sunset times registered during the experiment (05:40 to $05: 49 \mathrm{hrs}$ and 18:58 to 19:02 hrs respectively; Table 1a).

Wind speed, wind direction and temperature were averaged in the same $3 \mathrm{~h}$ bins. The thermocline was included as a categorical variable that indicates whether the receiver and the tags were in the same thermal layer. Its depth was defined as the inflection point of the temperature profile, i.e., the depth where the temperature gradient changes concavity (maximum slope method, Fiedler 2010). If the magnitude of the temperature gradient at the inflection depth was smaller than $0.1^{\circ} \mathrm{C} \mathrm{m}^{-1}$, we considered that no thermocline was present and receiver and tag were in the same layer.

Due to the large number of variables and therefore potential interactions, we included only those between distance and the environmental variables because we wanted to test the influence of environmental variables on the distance-detections relationship. All continuous variables were standardised to a scale with mean 0 and standard deviation 1 , which allowed a direct comparison of the predictors' coefficients (Table 1b).

We controlled for heterogeneity in the data introducing the receiver-tag combinations as random intercepts, and an autoregressive variance structure of order one that accounted for the temporal correlation between detections in adjacent time bins within each receiver-tag combination (Table 1c).

We detected a problematic correlation between thermocline and tag depth $(0.83$, bi-serial correlation coefficient), therefore we fitted two versions of the model, one excluding tag depth and other excluding thermocline. The $F$-statistics, Akaike Information Criterion or likehood 
ratio tests are not available for models estimated via Penalized-Quasi-Likehood, therefore we minimised both versions of the model using a backwards-stepwise regression procedure that eliminated the non-significant variables according to the $t$-statistic ( $\mathrm{p}$-value $<0.05$, Zuur et al. 2009)., We only report results for the model including thermocline: the relative importance and explanatory power of the predictors did not change between the two models, but the model including thermocline and excluding depth performed better.

For estimating detection range on the reef flat, we fitted a logistic regression to the average detections in $3 \mathrm{~h}$ bins (How and de Lestang 2012).

\section{Shib Habil}

Frequency analysis suggests a dominant peak at $24 \mathrm{~h}$ period and a peak at $\sim 7$ days (ESM Fig. $\mathrm{S} 1 \mathrm{~b})$. Because we used tags with a pseudo-random delay of $150 \pm 60 \mathrm{~s}$, we estimated detection probability for each tag-receiver combination as the number of detections recorded by the receiver divided by the maximum number of detections of the tag recorded by any receiver in the array, in $3 \mathrm{~h}$ time bins. The start times of the time bins were defined so that sunrise and sunset times (05:39 to $06: 17 \mathrm{hrs}$ and $18: 41$ to $19: 03 \mathrm{hrs}$ respectively) were balanced within the bins (Table 2a).

Because strong diurnal patterns in Malathu suggested an influence of biological noise (Table 2b), we additionally included in the Shib Habil model, the illuminated fraction of the moon because of a potential influence of moon phase on biological noise and the two-way interactions between receiver depth, moon and time, because the effect of biological noise might be different for receivers at different distances from the benthos. The random part of the model was structured in the same way as for Malathu (Table 2c). We did not find any problematic correlations $(>0.5)$ between explanatory variables. 


\section{Results}

\section{Malathu}

The strongest peak revealed by spectral analysis was located on a $24 \mathrm{~h}$ period (ESM Fig. S1a). Visual inspection of patterns in detection rate also revealed a marked change in detection probability (DP) between night and day at all distances and all depths (Fig. 3).

All figures and results are derived from the minimal model including thermocline (Table 1). Because of the large sample size, factor significances were often very high; hence we used effect sizes as indicators of the relative influence of variables.

Time of day, distance, topography and their interactions had the strongest effect on detection probability (DP) (Table 1b, Table 3a). The nominal detection range $\left(\mathrm{R}_{50 \%}\right.$, distance corresponding to DP 0.5 ) excluding the topography index (specific to this range test) is $\sim 230$ $\mathrm{m}$. When topography is included, the range is $135 \mathrm{~m}$ (Fig. 4a).

The significant interactions between distance and topography, time of day and wind speed suggest that the extent to which detectability declines with distance is influenced by these variables, particularly by topography. Specifically Distance:Topography reveals that as distance increases, topography becomes more relevant (Fig. 4c, Fig. 5). DP decreased when the array was on the windward side of the reef, but increased with larger wind speeds (Fig. $4 d)$.

The interaction Distance:Time indicates that the receivers further away are more sensitive to the drop in detections at night. Averaging all other effects, $\mathrm{R}_{50 \%}$ during nighttime was $103 \mathrm{~m}$ as opposed to $192 \mathrm{~m}$ during daytime (Fig. 4b).

On the reef flat $\mathrm{R}_{50 \%}$ was estimated to be at $9.4 \mathrm{~m}$ from the reef wall while $\mathrm{R}_{10 \%}$ was $14.8 \mathrm{~m}$. 


\section{Shib Habil}

Spectral analysis shows prominent peaks at periods of 1, 7 and 27 days (ESM Fig. S1b).

Visual inspection also revealed consistently fewer detections during night than during the day for all receivers at all depths.

Under average conditions, $\mathrm{R}$ is $540 \mathrm{~m}$. The model also shows that the variability of DP at all distances was very large, presumably because of the pseudo-random transmission delay of the tags used (Fig. 6a).

Distance, tag depth, receiver depth and time and its interactions had the largest coefficients and affected range the most (Table 2b, 3b). Distance had the stronger effect, but also interacted with receiver depth and moon phase. As in Malathu there is a significant difference between daytime and nighttime range (Fig. 6b). Tag-depth (which in this case covariates with closeness to the benthos) reduce $\mathrm{R}_{50 \%}$ by $43 \%$ (Fig. $6 \mathrm{c}$ )

There were significant interactions between the illuminated fraction of the moon and receiver depth and distance. In general, shallow receivers had more detections, but the difference in range between shallow and deep receivers was much more pronounced during new moon than full moon. Detection range during different illuminated fractions of the moon was less variable for deep receivers (502-492 m) than for shallow receivers (644-533 m, Fig. 6d).

\section{Discussion}

Topography and biological noise influenced the relationship between distance and detectability the most, overwhelming the effect of other environmental variables in both range tests.

As expected, DP decreases when the array is in the windward side of the reef. However we also found a positive effect of wind, where a negative effect would be expected (e.g., Ault et al. 2008; How and de Lestang 2012). It is possible that this effect is due to confounding 
between predictor variables, but it could also be caused by complex noise generation dynamics in shallow (reef) structures Alternatively increased wave energy may reduce the activity of benthic organisms; as some of these produce noise close to the tag's frequency (e.g., snapping shrimp), a small change in their activity could have a large effect on the signal. The thermocline had a very small negative effect on DP in Malathu, where the total difference in temperature across the water column was less than $3{ }^{\circ} \mathrm{C}$. Singh et al. (2009) note a much larger reduction (75\%) in detection range in stratified water with only $5{ }^{\circ} \mathrm{C}$ temperature difference. This suggests that the impact of the thermocline should be assessed in highly stratified water, especially when the study species moves across the thermocline. Additionally warmer surface temperatures might also stimulate increased activity in ectothermic organisms like snapping shrimps (Radford et al. 2008), which would negatively affect DP by producing noise in the tag's frequency range.

It is very likely that biological noise is responsible for a) the strong diurnal pattern in detections for both range tests, with smaller DP at night and b) the significant differences corresponding to the lunar phase in Shib Habil. Diel patterns in biological noise, with more noise occurring at night, have been directly recorded in several shallow water environments (Cato 1978; McCauley and Cato 2000; D'Spain and Batchelor 2006), together with evidence of decreasing acoustic detections at night (Payne et al. 2010).

Reduction in Detection Range $\left(\mathrm{R}_{50 \%}\right)$ at night was much greater in Malathu than Shib Habil ( $47 \%$ vs. $17 \%)$, most likely because the receivers in Malathu were much closer to the reef (2$3 \mathrm{~m}$ vs. up to $300 \mathrm{~m}$ for Shib Habil) and therefore to the source of biological noise. We also found a greater effect of time of day in receivers further away, likely due to a reduction of the Signal to Noise Ratio. It is worth nothing that not all acoustic studies find a diurnal pattern e.g., Welsh et al. (2012) and Ault et al. (2008), in 7 and $4 \mathrm{~d}$ coral reef range tests respectively. 
Shallow receivers had $17 \%$ greater detection range during new moon, whilst $\mathrm{R}$ in deep receivers was virtually unchanged during the lunar cycle. This pattern is opposite to that recorded in temperate reefs, where benthic animals increase sound production during new moon (Radford et al. 2008), resulting in a general increase in DP during full moon (How and de Lestang 2012). It is possible that noise production corresponding to time of day and lunar phase can differ depending on the habits of fauna in specific locations. While it might be troublesome to find the source of the noise that induces periodicity in DP, our results show that it should be considered.

The impact of reef topography is widely acknowledged but rarely quantified (e.g., Giacalone et al. 2005). On Malathu we show that our measure of topography can account for more than a $50 \%$ decrease in $\mathrm{R}_{50 \%}$ even though there was direct line of sight between tags and receivers. It was able to explain the non-monotonic decrease of detections across distance that would otherwise be attributed to random differences in receiver location.

Smaller tags (such as Vemco V9s), also commonly used in coral reefs, are anticipated to have a smaller Signal to Noise Ratio; therefore we would expect a similar impact from topography but a possibly larger influence of background noise.

Methods for finding centers of activity (COA) based on relative detections at different receivers (Simpfendorfer and Heupel 2002) have been increasingly popular for improving the positioning of coral reef animals with coded passive acoustic tags (Marshell et al. 2012; Knip et al. 2012). COA and other inferential methods based on linear decrease of DP with distance must be used with great care in coral reefs. Methods based on ping time of arrival may be more reliable than $\mathrm{COA}$, but multipath and low signal to noise ratio may play a dominant role in the positioning error (Smith et al. 1998). We show that topographic features are largely influential even in reefs with relatively low structural complexity. Triangulating with relative detections or time of arrival may not accurately predict centers of activity but instead show 
centers of detectability. Higher numbers of detections could reflect lower topographic complexity rather than true fish behaviour.

As expected, distance itself was a prime determinant of detection probability. Our detection ranges were (consistent with other coral reef studies) smaller than those in open-water environments. The V13s in Malathu gave an $\mathrm{R}_{50 \%}$ of $134 \mathrm{~m}$ and $\mathrm{R}_{10 \%}$ of $192-280 \mathrm{~m}$ compared to DP $<85 \%$ at $350-900 \mathrm{~m}$ in an estuary (Espinoza et al. 2011), or detecting tags to $335-385$ $\mathrm{m}$ in open water (Girard et al. 2008).

Deeper tags and receivers had lower DP in Shib Habil, likely due to closeness to the benthos, but it is not possible to separate the potential negative effects of blocking by the benthos, increases in biological noise, or increases in turbidity. In Malathu, a reef with almost vertical walls, tag depth played a comparatively unimportant role in detection probability. Given the water was clear, all tags were at equal distances from the reef wall and depth was only measured to $57 \mathrm{~m}$, depth here probably merely represents a slightly longer direct-path distance between tags and receivers.

Our study suggests that on coral reefs, it is especially important to take into account the effect of local topography and biological noise and corrections should be made before interpreting data to accurately reflect animal behaviour. Payne et al. (2010) show how not doing so might lead to completely opposite patterns in animal activity. Short-term range tests that only analyze the effect of distance at one point in time (not accounting for biological noise), or at one location (not accounting for topography), are likely to lead to biased conclusions. Acoustic telemetry has many benefits for studying the behaviour of marine animals, however, it must be used with care in coral reef environments. The assumption that weather-related noise is the most common factor limiting detection range of acoustic tags (Girard et al. 2008) should not be extrapolated to coral reefs. Long-term range tests in the study location prior to tagging animals and/or at least monitoring the array over the course of the study with sentinel 
tags are prudent (if not necessary) measures to facilitate proper interpretation of data

generated in passive telemetry.

ACKNOWLEDGEMENTS - We thank Bertrand Rioux, Gerrit Nanninga, Noah DesRosiers, Mae Noble, Jesse

Cochran, Lautaro Rayo and the staff of the Coastal and Marine Resources Core Lab at King Abdullah University

of Science and Technology for field assistance and materials; Dale Webber and Tim Stone for technical

assistance with tag specifications and experimental design; and Andrea Manica, Christoph Rohner and four

anonymous referees for helpful suggestions to the manuscript. Thanks to the NOAA National Climatic Data

Center, the US Naval Observatory and the Institut für Meereskunde of the University of Hamburg for the freely

available data.

\section{Literature cited}

Ault JS, Smith SG, Bohnsack JA, Luo J, Zurcher N, Vaughan NR, Farmer NA, Harper DE, McCellan DB (2008) Fishery-independent monitoring of coral reef fishes, coral reefs, and macro-invertebrates in the Dry Tortugas: Final Report. Univ. Miami, Rosenstiel School of Marine and Atmospheric Science, p 90

Bradford R, Bruce BD, McAuley R, Robinson G (2011) An evaluation of passive acoustic monitoring using satellite communication technology for near real-time detection of tagged animals in a marine setting. Open Fish Sci J 4:10-20

Caruthers JW (1977) Chapter 5 Sonar wquations and parameters. In: Caruthers JW (ed) Fundamentals of marine acoustics. Elsevier, pp 63-67.

Cato DH (1978) Marine biological choruses observed in tropical waters near Australia. J Acoust Soc Am 64:736-743

Cato DH (2008) Ocean ambient noise: Its measurement and its significance to marine animals. Proceedings of the Conference on Underwater Noise Measurement, Impact and Mitigation. Institute of Acoustics, Southampton, pp 1-9

Claisse JT, Clark TB, Schumacher BD, McTee SA, Bushnell ME, Callan CK, Laidley CW, Parrish JD (2011) Conventional tagging and acoustic telemetry of a small surgeonfish, Zebrasoma flavescens, in a structurally complex coral reef environment. Environ Biol Fish 91:185-201

Clements S, Jepsen D, Karnowski M, Schreck CB (2005) Optimization of an acoustic telemetry array for detecting transmitter-implanted fish. N A J Fish Manag 25:429-436

DSpain GL, Batchelor HH (2006) Observations of biological choruses in the Southern California Bight: A chorus at midfrequencies. J Acoust Soc Am 120:1942-1955

Espinoza M, Farrugia TJ, Webber DM, Smith F, Lowe CG (2011) Testing a new acoustic telemetry technique to quantify long-term, fine-scale movements of aquatic animals. Fish Res 108:364-371

Fiedler PC (2010) Comparison of objective descriptions of the thermocline. Limnol Oceanogr 8:313-325

Giacalone VM, Anna GD, Garofalo G, Collins K, Badalamenti F (2005) Estimation of positioning error from an array of automated omni-directional receivers in an artificial reef area. In: Spedicato MT, Lembo G, Marmulla G (eds) Aquatic telemetry: advances and applications. Proceedings of the Fifth Conference on Fish Telemetry held in Europe. FAO/COISPA, Ustica, pp 9-13

Girard C, Dagorn L, Taquet M, Aumeeruddy R, Peignon C, Benhamou S (2008) Homing abilities of dolphinfish (Coryphaena hippurus) displaced from fish aggregating devices (FADs) determined using ultrasonic telemetry. Aquat Living Resour 321:313-321

Halttunen E, Rikardsen AH, Davidsen JG, Thorstad EB Dempson JB (2009) Survival, migration speed and swimming depth of Atlantic salmon kelts during sea entry and fjord migration. In: Nielsen JL, Arrizabalaga H, Fragoso N, Hobday A, Lutcavage H, Sibert J (eds) Tagging and tracking of marine animals with electronic devices. Springer Netherlands, Dordrecht, pp 35-49

Heupel M, Semmens JM, Hobday AJ (2006) Automated acoustic tracking of aquatic animals: scales, design and deployment of listening station arrays. Mar Freshw Res 57:1-13 
Hobday AJ, Pincock DG (2011) Estimating detection probabilities for linear acoustic monitoring arrays. In: McKenzie JR, Parsons B, Seitz AC, Kopf R, Mesa M, Phelps Q (eds) Advances in fish tagging and marking technology. American Fisheries Society Symposium 79, Bethesda, pp 325-346

How JR, de Lestang S (2012) Acoustic tracking: issues affecting design, analysis and interpretation of data from movement studies. Mar Freshw Res 63:312-324

Humston R, Ault J, Larkin M, Luo J (2005) Movements and site fidelity of the bonefish Albula vulpes in northern Florida Keys determined by acoustic telemetry. Mar Ecol Prog Ser 291:237-248

Kennedy E (2007) Singing reefs : an investigation into the acoustic environment of the Las Perlas archipelago, Panama. PhD thesis, Heriot-Watt University, p 13

Knip DM, Heupel MR, Simpfendorfer CA (2012) Habitat use and spatial segregation of adult spottail sharks Carcharhinus sorrah in tropical nearshore waters. J Fish Biol 80:767-784

Koopmans LH (1995) The spectral analysis of time series. Academic Press, London, pp 257-294

Marshell A, Mills JS, Rhodes KL, McIlwain J (2011) Passive acoustic telemetry reveals highly variable home range and movement patterns among unicornfish within a marine reserve. Coral Reefs 30:631-642

McCauley RD, Cato DH (2000) Patterns of fish calling in a nearshore environment in the Great Barrier Reef. Philos Trans R Soc Lond B Biol Sci 355:1289-1293

Melnychuk MC (2012) Detection efficiency in telemetry studies: definitions and evaluation methods. In: Adams NS, Beeman JW, Eiler JH (eds) Telemetry techniques: a user guide for fisheries research. American Fisheries Society, Bethesda, pp 339-357

Melnychuk MC, Walters CJ (2010) Estimating detection probabilities of tagged fish migrating past fixed receiver stations using only local information. Can J Fish Aquat Sci 67:641-658

Morisaka T, Shinohara M, Nakahara F, Akamatsu T (2005) Effects if ambient noise on the whistkes of indopacific bottlenose dolphin populations. J Mammal 86:541-546

Payne N, Gillanders B, Webber D, Semmens JM (2010) Interpreting diel activity patterns from acoustic telemetry: the need for controls. Mar Ecol Prog Ser 419:295-301

R Development Core Team (2011) R: A Language and Environment for Statistical Computing. R Foundation for Statistical Computing 1:409

Radford CA, Jeffs AG, Tindle CT, Montgomery JC (2008) Temporal patterns in ambient noise of biological origin from a shallow water temperate reef. Oecologia 156:921-929

Reynolds RW, Smith TM, Liu C, Chelton DB, Casey KS, Schlax MG (2007) Daily high-resolution-blended analyses for sea surface temperature. J Clim 20:5473-5496

Siderius M, Porter MB, Hursky P, McDonald V (2007) Effects of ocean thermocline variability on noncoherent underwater acoustic communications. J Acoust Soc Am 121:1895-1908

Simpfendorfer C, Heupel M (2002) Estimation of short-term centers of activity from an array of omnidirectional hydrophones and its use in studying animal movements. Can J Fish Aquat Sci 32:23-32

Simpfendorfer C, Heupel M, Collins AB (2008) Variation in the performance of acoustic receivers and its implication for positioning algorithms in a riverine setting. Can J Fish Aquat Sci 65:482-492

Singh L, Downey NJ, Roberts MJ, Webber DM, Smale MJ, VanDenBerg MA, Harding RT, Engelbreecht DC, Blows BM (2009) Design and calibration of an acoustic telemetry system subject to upwelling events. Afr J Mar Sci 31:355-364

Smith GW, Urquhart GG, Maclennan DN, Sarno B (1998) A comparison of theoretical estimates of the errors associated with ultrasonic tracking using a fixed hydrophone array and field measurements. Hydrobiologia 371-372:9-17

Szedlmayer ST, Schroepfer RL (2005) Long-term residence of red snapper on artificial reefs in the northeastern Gulf of Mexico. Trans Am Fish Soc 134:315-325.

Topping D, Lowe C, Caselle J (2006) Site fidelity and seasonal movement patterns of adult California sheephead Semicossyphus pulcher (Labridae): an acoustic monitoring study. Mar Ecol Prog Ser 326:257-267

Venables WN, Ripley BD (2002) Modern Applied Statistics with S, Springer, p 495

Vijayabaskar V, Rajendran V (2010) Wind dependence of ambient noise in shallow water of Arabian Sea during pre-monsoon. Recent advances in space technology services and climate change. Chennai, pp 372-375

Welsh JQ, Fox RJ, Webber DM, Bellwood DR (2012) Performance of remote acoustic receivers within a coral reef habitat: implications for array design. Coral Reefs 31:693-702

Wenz G (1962) Acoustic ambient noise in the ocean: Spectra and sources. J Acoust Soc Am 34:1936-195

Zhang H-M, Bates JJ, Reynolds RW (2006) Assessment of composite global sampling: Sea surface wind speed. Geophys Res Lett 33:1-5

Zuur AF, Ieno EN, Walker NJ, Saveliev AA, Smith GM (2009) Mixed Effects Models and Extensions in Ecology with R.Springer, pp 90-93 

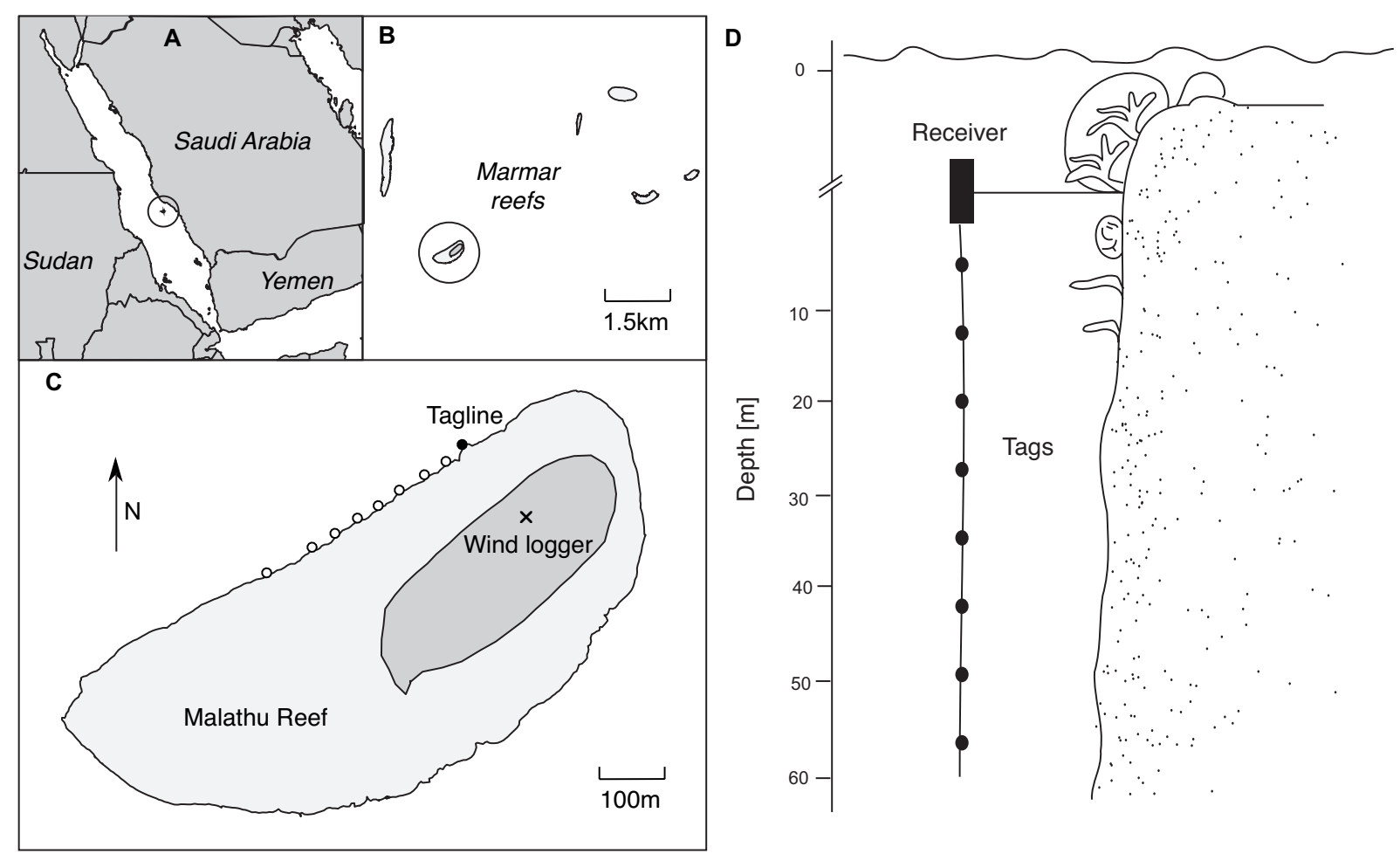

Fig. 1 a b Maps showing the location of the study site $\mathbf{c}$ Map showing the location of tagline, receivers and the wind logger in Malathu. Receivers (white circles) were located at intervals of $36 \pm 7.5 \mathrm{~m}$ (mean $\pm \mathrm{SD}$ ). Tags were installed along with the first receiver (black circle) and the wind logger was installed on the highest point of the sand bank. $\mathbf{d}$ Receivers (black rectangle) were attached to the tip of a $3 \mathrm{~m}$ long aluminium pole bolted perpendicularly to the reef wall with the hydrophone tip pointing down, free of any blocking structures. These pole moorings were installed at $6 \mathrm{~m}$ depth, just below the reef crest. The tagline comprised eight tags (solid circles) installed at depth intervals of $7.1 \pm 0.4 \mathrm{~m}($ mean $\pm \mathrm{SD})$ on a line attached to the first pole mooring. 

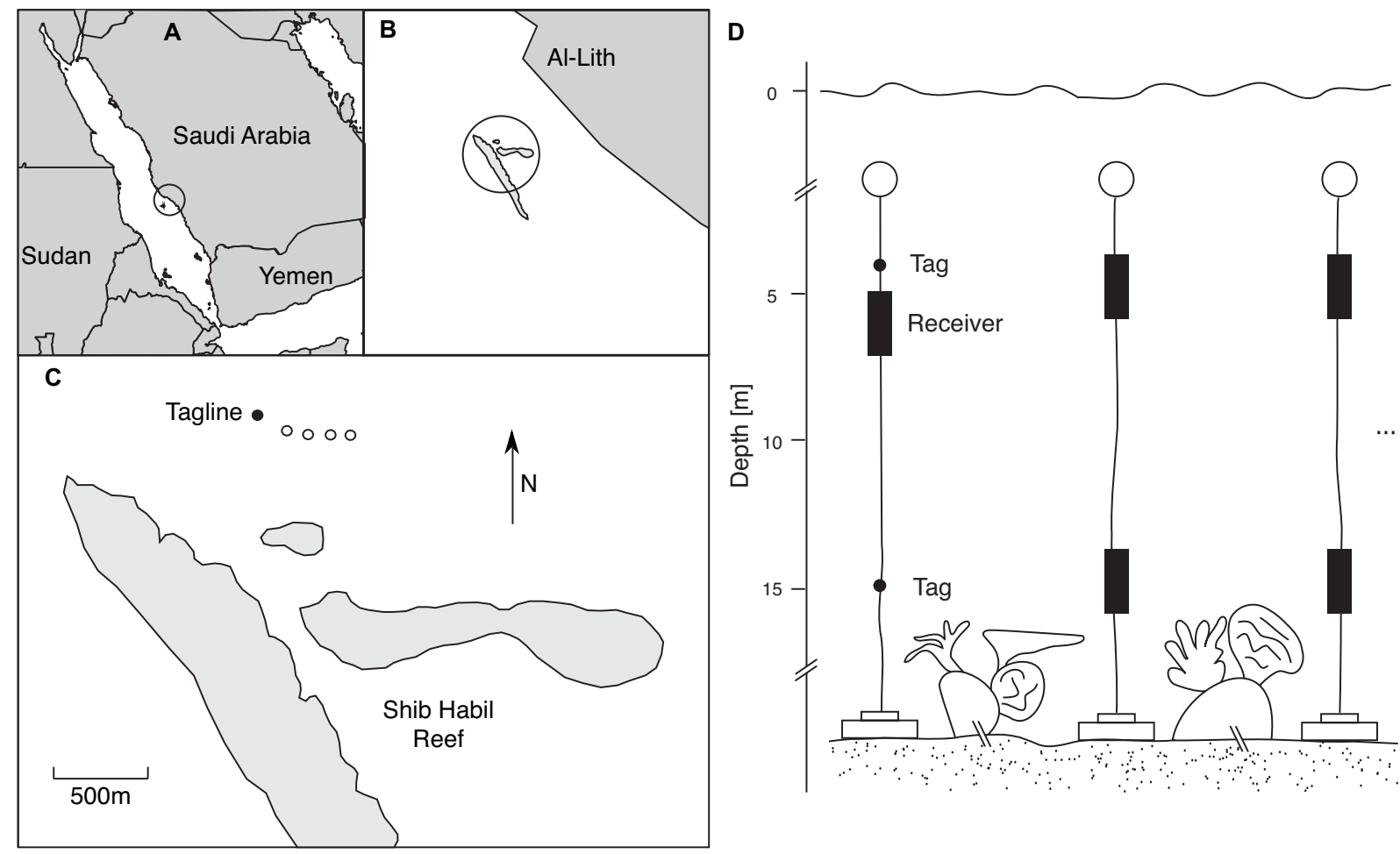

Fig. 2 a b Maps showing the location of Shib Habil. c Map showing the location of the range test near Shib

Habil. Receivers (circles) were installed at 0, 170, 280, 385 and $485 \mathrm{~m}$ from the tag line (black circle). d

Moorings consisted of a rope and float attached to a $25 \mathrm{~kg}$ concrete block. All tags and receivers were either at 5 $\mathrm{m}$ (shallow) or $15 \mathrm{~m}$ (deep). The first mooring held one shallow receiver and one shallow and one deep tag. The subsequent four moorings each contained just a pair of receivers.

A
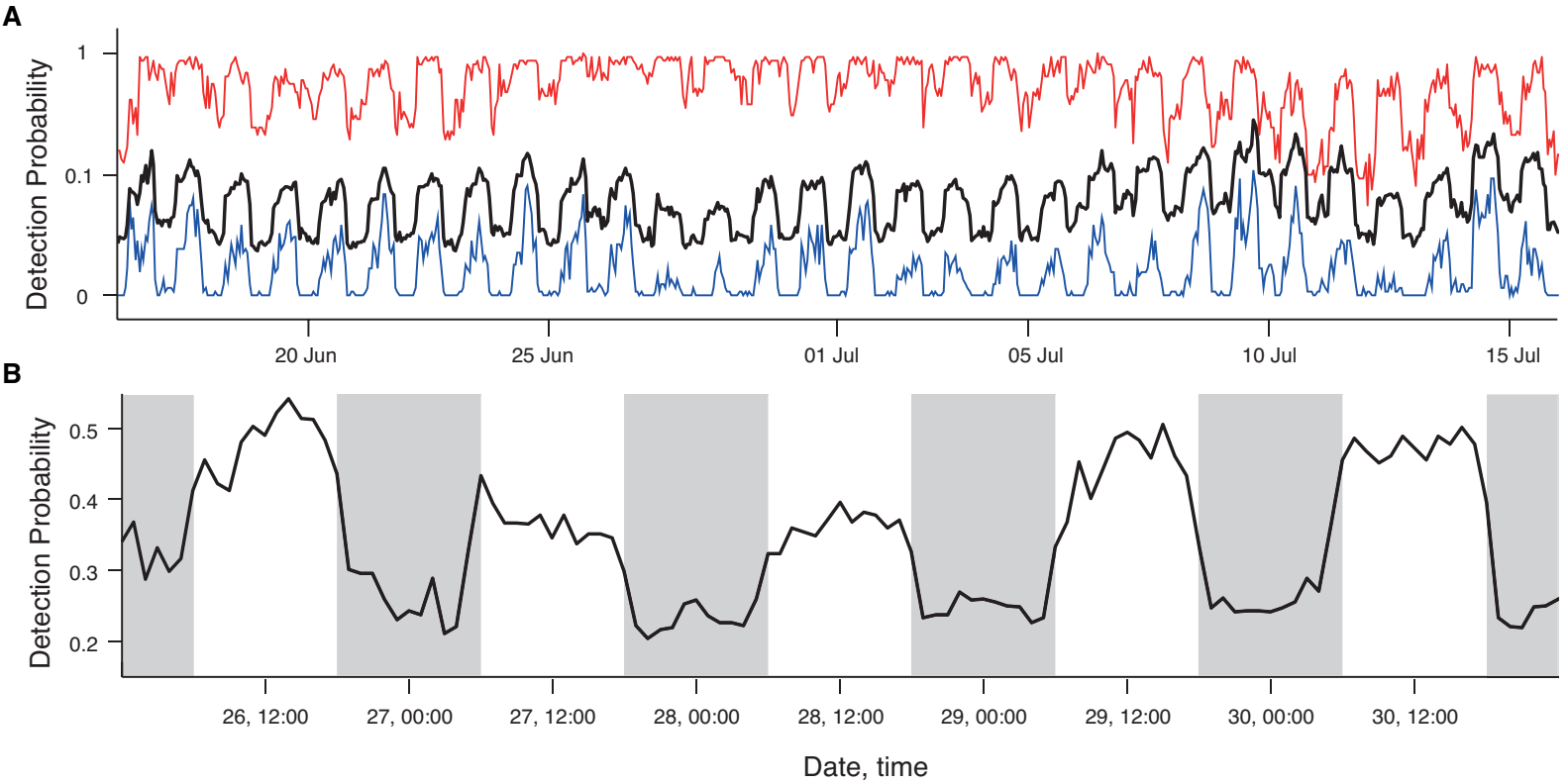

Fig. 3 a Average observed detection probability (DP) in $1 \mathrm{~h}$ bins of the total amount of detections on all receivers for the duration of the Malathu range test (black line). In red DP for the receiver at $0 \mathrm{~m}$ from the 
tagline; in blue DP for the receiver at $325 \mathrm{~m}$ b Close up of the average observed probability for five days from 26 Jun 00:00 to $1 \mathrm{Jul}$ 00:00 showing the diurnal pattern in detections (shaded areas represent nighttime from 18:00 to $06: 00 \mathrm{hrs})$.
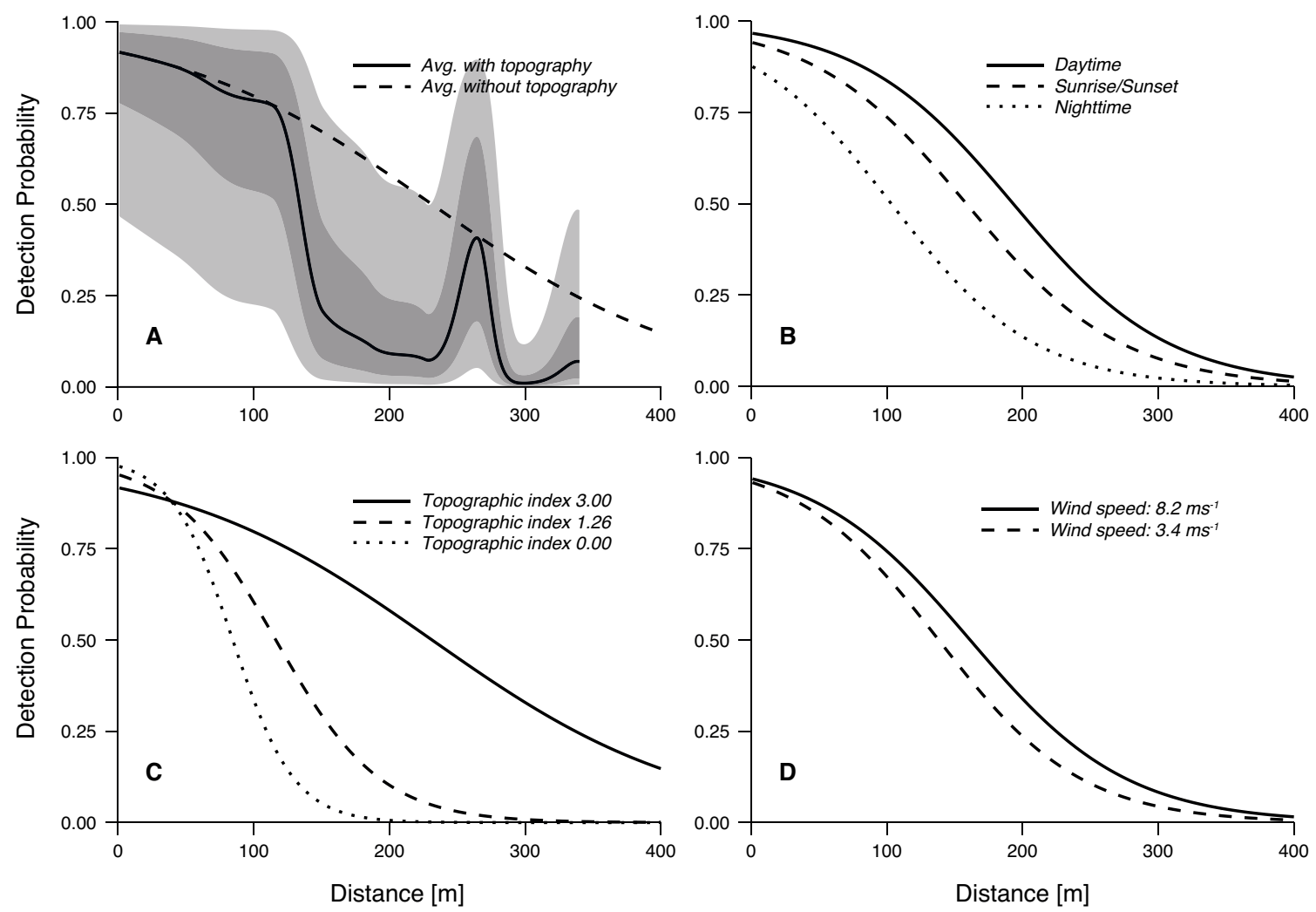

Fig. 4 a Predicted detection probability (DP) in the Malathu range test at different distances. The dashed line represents the predicted DP assuming a range test deprived of topographical complexity under average conditions. The solid line is the average predicted DP when the topographical index for each receiver is included. The light grey area represents $\mathrm{DP} \pm \mathrm{SD}$; the dark grey area represents the SD accounted for by the random effects (tag-receiver pairs). b Effect of time of day on DP: daytime (solid line), sunrise and sunset (dashed line) and nighttime (dotted line). c Effect of topography on DP: average conditions without topographic complexity (solid line), for the smallest measured topographic index (dashed line) and for a theoretical sound path that touches the reef (dotted line, extrapolated). d Effect of wind speed: DP under a $8.2 \mathrm{~ms}^{-1}$ wind speed (solid line) and under $3.4 \mathrm{~ms}^{-1}$ (dashed line). The wind speeds compared correspond to the $\pm 1 \mathrm{SD}$. 


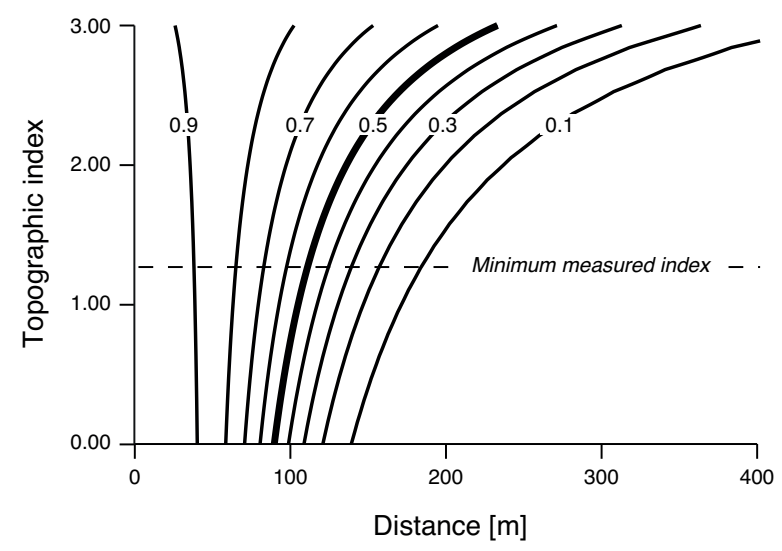

Fig. 5 Contour plot of detection probability varying with both distance and topography.
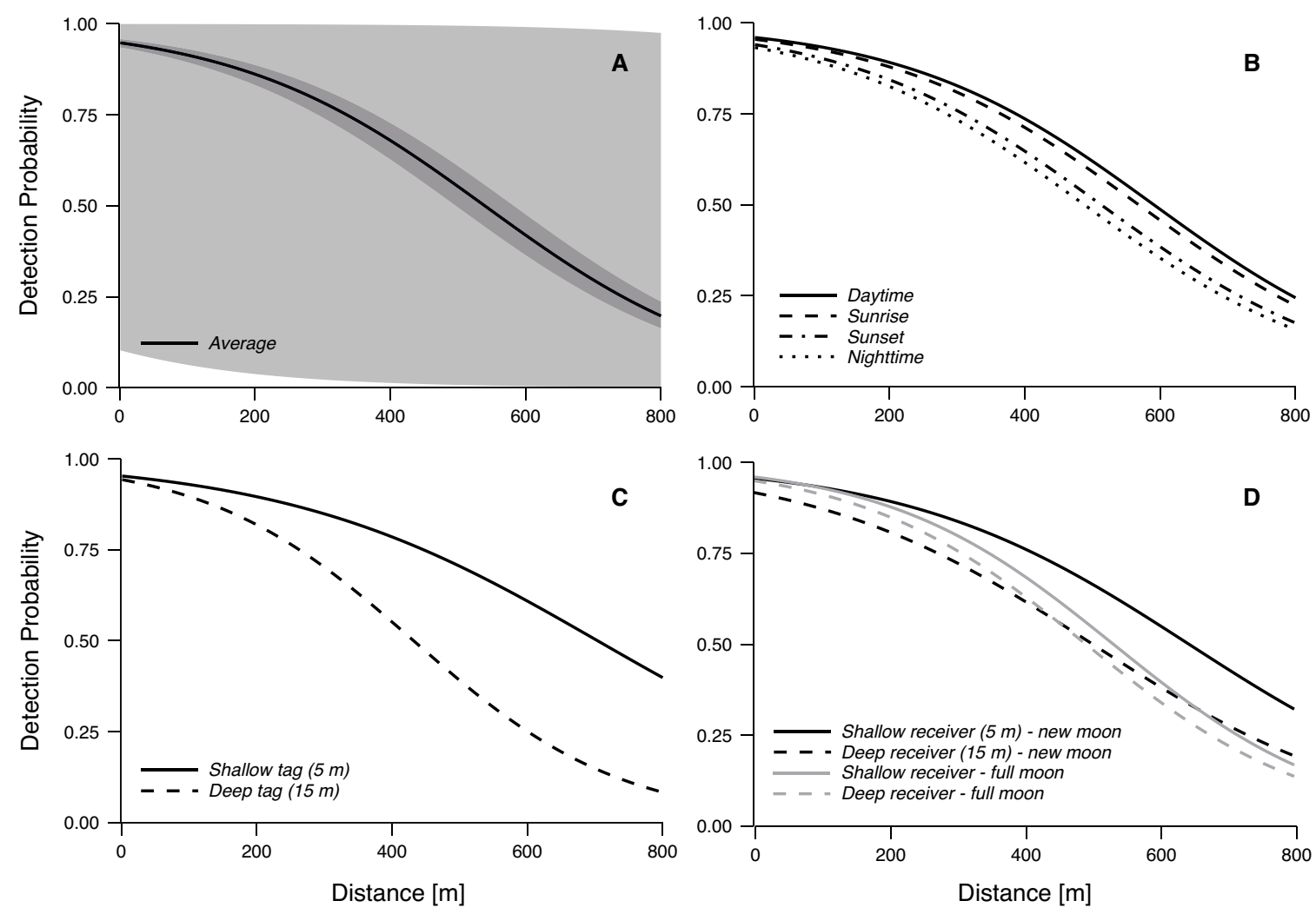

Fig. 6 a Predicted detection probability (DP) in the Shib Habil range test at different distances. The solid line represents the average predicted DP. The light grey shaded area represents $\mathrm{DP} \pm \mathrm{SD}$; the dark gray area represents the SD accounted for by the random effects (tag-receiver pairs). b Effect of time of day on DP: daytime (solid line), sunrise (dashed line) and sunset (dash-dot line) and nighttime (dotted line). c Effect of tag depth on DP: tags at $5 \mathrm{~m}$ depth (solid line) and tags at $15 \mathrm{~m}$ depth (dashed line); the sea bottom was $20 \mathrm{~m}$. d Effect of moon phase and receiver depth on DP: New moon in black line, full moon in grey line; receivers at $5 \mathrm{~m}$ depth in solid lines and receivers at $15 \mathrm{~m}$ depth in dashed lines. 
Table 1 Summary of the GLMM of Detection Probability (DP) in Malathu. Mean values are reported \pm SD. Estimates are shown for logit(DP). Models were minimised using backwardsstepwise regression ( $t$-statistic).

\begin{tabular}{|c|c|c|c|c|c|c|c|}
\hline \multirow[t]{2}{*}{ a) } & \multicolumn{4}{|c|}{ Description } & \multicolumn{3}{|c|}{ Range Mean } \\
\hline & $\begin{array}{l}\text { Number } \\
\text { known nu } \\
\text { Bins: } 1: 5\end{array}$ & \multicolumn{3}{|c|}{$\begin{array}{l}\text { Number of detections recorded by a receiver divided by the } \\
\text { known number of transmissions emitted by a tag in a } 3 \mathrm{~h} \text { bin. } \\
\text { Bins: } 1: 52,4: 52,7: 52,10: 52,13: 52,16: 52,19: 52,22: 52\end{array}$} & $0-1$ & \multicolumn{2}{|c|}{$0.38 \pm 0.40$} \\
\hline \multirow[t]{19}{*}{ b) } & Fixed Effects & $\begin{array}{l}\text { Range / } \\
\text { Categories }\end{array}$ & $\begin{array}{l}\text { Variable description } \\
\text { description }\end{array}$ & Estimate & Error & t-value & P-value \\
\hline & Intercept & - & - & -1.412 & 0.155 & -9.06 & $<0.001$ \\
\hline & Distance & $0-325 \mathrm{~m}$ & Mean: $163.1 \pm 108.2$ & -2.084 & 0.193 & -10.76 & $<0.001$ \\
\hline & Time & Sunrise & From $04: 52$ to $07: 52$ & 1.091 & 0.025 & 42.51 & $<0.001$ \\
\hline & & Day-time & From $07: 52$ to $16: 52$ & 1.689 & 0.029 & 57.15 & $<0.001$ \\
\hline & & Sunset & From $16: 52$ to $19: 52$ & 1.082 & 0.025 & 42.19 & $<0.001$ \\
\hline & & Night-time & From $19: 52$ to $04: 52$ & \multicolumn{4}{|c|}{ - Baseline category - } \\
\hline & Topography Index & $1.26-3.00$ & Mean: $2.32 \pm 0.69$ & 1.061 & 0.146 & 7.23 & $<0.001$ \\
\hline & Wind Speed & $0-12.5 \mathrm{~m} \mathrm{~s}^{-1}$ & Mean: $6.00 \pm 2.36$ & 0.232 & 0.014 & 16.54 & $<0.001$ \\
\hline & Wind Direction & $1-180^{\circ}$ & Mean: $52.18^{\circ} \pm 27.2^{\circ}$ & 0.073 & 0.010 & 7.04 & $<0.001$ \\
\hline & \multirow[t]{2}{*}{ Thermocline } & Same layer & Freq.: $62 \%$ of times & 0.042 & 0.020 & 2.06 & 0.0337 \\
\hline & & Diff. layer & Freq.: $38 \%$ of times & \multicolumn{4}{|c|}{ - Baseline category - } \\
\hline & Distance: Wind Speed & - & - & 0.091 & 0.014 & 6.23 & $<0.001$ \\
\hline & \multirow[t]{3}{*}{ Distance: Time } & Sunrise & - & 0.172 & 0.026 & 6.48 & $<0.001$ \\
\hline & & Day-time & - & 0.166 & 0.030 & 5.37 & $<0.001$ \\
\hline & & Sunset & - & 0.159 & 0.026 & 6.01 & $<0.001$ \\
\hline & Distance : Topography I. & - & - & 0.846 & 0.243 & 3.48 & 0.008 \\
\hline & Distance : Thermocline* & Same layer & - & $0.01 *$ & $0.02 *$ & $0.9^{*}$ & $0.375^{*}$ \\
\hline & Distance : Wind Direction* & - & - & $0.01 *$ & $0.01 *$ & $0.7 *$ & $0.433 *$ \\
\hline
\end{tabular}

\begin{tabular}{lll} 
c) Covariance structure & Description & Estimate \\
\hline Random effect & One intercept for each receiver- & SD of the random intercept: 1.154 \\
& transmitter combination (80 groups) & Residual SD: 2.531 \\
$1^{\text {at }}$ order autoregressive & Controls the temporal autocorrelation & $\Phi=0.725$ \\
structure & within receiver-transmitter combinations &
\end{tabular}

* Effects NOT present in the minimal model: the $\mathrm{t}$ and $\mathrm{P}$ values presented correspond to those obtained in the candidate model that they were removed from 
Table 2 Summary of the GLMM of Detection Probability (DP) in Shib Habil. Mean values are reported \pm SD. Estimates are shown for logit(DP). See Table 1 heading for details.

a)

\begin{tabular}{llll} 
Response & Description & Range & Mean \\
\hline Detection & Number of detections recorded by a receiver divided by the & $0-1$ & $0.75 \pm 0.31$ \\
Probability & known number of transmissions emitted by a tag in a 3h bin. & & \\
& Bins: $1: 55,4: 55,7: 55,10: 55,13: 55,16: 55,19: 55,22: 55$ & &
\end{tabular}

\begin{tabular}{|c|c|c|c|c|c|c|}
\hline Fixed Effects & $\begin{array}{l}\text { Range / } \\
\text { Categories }\end{array}$ & $\begin{array}{l}\text { Variable } \\
\text { description }\end{array}$ & Estimate & Error & t-value & P-value \\
\hline Intercept & - & - & 1.110 & 0.066 & 16.44 & $<0.001$ \\
\hline Time & Sunrise & From $04: 55$ to $07: 55$ & 0.432 & 0.025 & 16.73 & $<0.001$ \\
\hline & Day-time & From $07: 55$ to $16: 55$ & 0.552 & 0.028 & 19.30 & $<0.001$ \\
\hline & Sunset & From $16: 55$ to $19: 55$ & 0.133 & 0.024 & 5.406 & $<0.001$ \\
\hline & Night-time & From $19: 55$ to $04: 55$ & \multicolumn{4}{|c|}{ - Baseline category - } \\
\hline Distance & $0-485 \mathrm{~m}$ & Mean: $282.0 \pm 157.2 \mathrm{~m}$ & -0.847 & 0.070 & -11.84 & $<0.001$ \\
\hline Tag Depth & $5-15 \mathrm{~m}$ & Mean: $12.5 \pm 7.5 \mathrm{~m}$ & -0.431 & 0.065 & -6.19 & 0.0001 \\
\hline Rec. Depth & $5-15 m$ & Mean: $12.5 \pm 7.5 \mathrm{~m}$ & -0.267 & 0.067 & -3.85 & 0.0027 \\
\hline Surface Temperature & $27.9-32.0^{\circ}$ & Mean: $30.21 \pm 0.92^{\circ}$ & -0.068 & 0.027 & -2.53 & 0.0113 \\
\hline Moon & $0-100 \%$ & Mean: $47.8 \pm 34.0 \%$ & -0.042 & 0.032 & -1.29 & 0.1963 \\
\hline Distance: Tag Depth & - & - & -0.175 & 0.068 & -2.54 & 0.0274 \\
\hline Distance: Moon Phase & - & - & -0.092 & 0.033 & -2.79 & 0.0052 \\
\hline Moon Phase: Rec Depth & - & - & 0.109 & 0.028 & 3.80 & 0.0001 \\
\hline \multirow[t]{3}{*}{ Moon Phase: Time } & Sunrise & - & -0.018 & 0.025 & -0.74 & 0.4592 \\
\hline & Day-time & - & 0.077 & 0.027 & 2.78 & 0.0054 \\
\hline & Sunset & - & 0.044 & 0.025 & 1.84 & 0.0655 \\
\hline \multirow[t]{3}{*}{ Rec. Depth: Time } & Sunrise & - & 0.010 & 0.025 & 0.39 & 0.6931 \\
\hline & Day-time & - & 0.072 & 0.025 & 2.53 & 0.0112 \\
\hline & Sunset & _- & 0.062 & 0.028 & 2.53 & 0.0112 \\
\hline Distance: Rec. Depth* & - & - & $-0.14 *$ & $0.06^{*}$ & $-2.2^{*}$ & $0.054 *$ \\
\hline Distance: Surface Temp.* & _ & _ & $0.05^{*}$ & $0.03 *$ & $1.7 *$ & $0.082 *$ \\
\hline Distance: Time* & Sunrise & - & $-0.03 *$ & $0.03 *$ & $-1.2 *$ & $0.241 *$ \\
\hline & Day-time & _- & $-0.04 *$ & $0.03 *$ & $-1.3^{*}$ & $0.189 *$ \\
\hline & Sunset & - & $0.03 *$ & $0.02 *$ & $1.1^{*}$ & $0.256^{*}$ \\
\hline Covariance structure & Description & & \multicolumn{4}{|c|}{ Estimate } \\
\hline Random effect & \multirow{2}{*}{\multicolumn{2}{|c|}{$\begin{array}{l}\text { One intercept for each receiver- } \\
\text { transmitter combination ( } 16 \text { groups) }\end{array}$}} & \multirow{3}{*}{\multicolumn{4}{|c|}{$\begin{array}{l}\text { SD of the random in } \\
\text { Residual SD: } 5.068 \\
\Phi=0.694\end{array}$}} \\
\hline & & & & & & \\
\hline $\begin{array}{l}1^{\text {st }} \text { order autoregressive } \\
\text { structure }\end{array}$ & \multicolumn{2}{|c|}{$\begin{array}{l}\text { Controls the temporal autocorrelation } \\
\text { within receiver-transmitter combinations }\end{array}$} & & & & \\
\hline
\end{tabular}

* Effects NOT present in the minimal model. The showed $\mathrm{t}$ and $\mathrm{P}$ values presented correspond to those obtained in the candidate model that they were removed from 
Table 3 Relative influences of individual parameters on $\mathrm{R}_{0.5}$ when all other parameters are averaged

a) Malathu

\begin{tabular}{lr} 
Variable & Rel. decrease in $\mathrm{R}_{50 \%}$ \\
\hline Night-time vs. day-time & $47 \%$ \\
1.6 vs. 3 m wide sound path & $50 \%$ \\
3.4 vs. $8.2 \mathrm{~m} \mathrm{~s}^{-1}$ wind & $50 \%$ \\
Same thermal layer vs. different layer & $14 \%$ \\
Leeward vs. windward 6 m s"- wind $^{\dagger}$ & $2 \%$ \\
& $16 \%$
\end{tabular}

b) Shib Habil

Variable

Rel. decrease in $\mathrm{R}_{50 \%}$

Night-time vs. day-time $17 \%$

Tag at 5 vs. $15 \mathrm{~m}$

$43 \%$

New vs. full moon for rec. at $5 \mathrm{~m}$

$17 \%$

New vs. full moon for rec. at $15 \mathrm{~m}$

$2 \%$

$29.2^{\circ}$ vs. $31.1^{\circ} \mathrm{C}^{*}$ surface temperature

$5 \%$

* Values compared correspond to $\pm 1 \mathrm{SD}$ on the measured variables

$\dagger$ Average wind speed 